\title{
Identifying and managing osteoporosis before and after COVID-19: rise of the remote consultation?
}

\author{
Z. Paskins $^{1}$ (D) $\cdot$ F. Crawford-Manning ${ }^{1} \cdot$ L. Bullock $^{2}$ (D) $\cdot$ C. Jinks ${ }^{2}$ (D)
}

Received: 29 April 2020 / Accepted: 11 May 2020 / Published online: 16 June 2020

(C) International Osteoporosis Foundation and National Osteoporosis Foundation 2020

\begin{abstract}
Summary The COVID-19 pandemic is influencing methods of healthcare delivery. In this short review, we discuss the evidence for remote healthcare delivery in the context of osteoporosis.

Introduction The COVID-19 pandemic has undoubtedly had, and will continue to have, a significant impact on the lives of people living with, and at risk of, osteoporosis and those caring for them. With osteoporosis outpatient and Fracture Liaison Services on pause, healthcare organisations have already moved to delivering new and follow-up consultations remotely, where staffing permits, by telephone or video.

Methods In this review, we consider different models of remote care delivery, the evidence for their use, and the possible implications of COVID-19 on osteoporosis services.

Results Telemedicine is a global term used to describe any use of telecommunication systems to deliver healthcare from a distance and encompasses a range of different scenarios from remote clinical data transfer to remote clinician-patient interactions. Across a range of conditions and contexts, there remains unclear evidence on the acceptability of telemedicine and the effect on healthcare costs. Within the context of osteoporosis management, there is some limited evidence to suggest telemedicine approaches are acceptable to patients but unclear evidence on whether telemedicine approaches support informed drug adherence. Gaps in the evidence pertain to the acceptability and benefits of using telemedicine in populations with hearing, cognitive, or visual impairments and in those with limited health literacy.

Conclusion There is an urgent need for further health service evaluation and research to address the impact of remote healthcare delivery during COVID-19 outbreak on patient care, and in the longer term, to identify acceptability and cost- and clinicaleffectiveness of remote care delivery on outcomes of relevance to people living with osteoporosis.
\end{abstract}

Keywords COVID-19 · FLS · Osteoporosis · Telemedicine

The COVID-19 pandemic has undoubtedly had, and will continue to have, a significant impact on the lives of people living with, and at risk of, osteoporosis and the people who care for them. Social distancing and self-isolation are likely to be resulting in changes in activity levels (and consequently may impact rates of falls and fractures), physical and mental health, and health-seeking behaviours. Osteoporosis treatments, such as intravenous bisphosphonates, or subcutaneous denosumab

Z. Paskins

z.paskins@keele.ac.uk

1 School of Primary, Community and Social Care, Keele University \& Haywood Academic Rheumatology Centre, Stoke-on-Trent, UK

2 School of Primary, Community and Social Care, Keele University, Newcastle-under-Lyme, UK have been delayed or withdrawn as hospitals and healthcare services enact changes to reduce all but essential face-to-face contact, particularly in those deemed most at risk of COVID19. Bone densitometry is not being performed, many Fracture Liaison Services (FLSs) have ceased activity, and many clinicians previously delivering osteoporosis care will have been redeployed. Guidance is clear that non-urgent services should be delivered remotely where possible, leading to experimentation and, in some instances rapid uptake of hitherto unused remote healthcare delivery technologies [1-3]. In this paper, we consider different models of remote care delivery, the evidence for their use, and the possible implications of COVID19 on osteoporosis services.

Telemedicine and telehealth are global terms used to describe any use of telecommunication systems to deliver healthcare from a distance [4], and encompasses remote 
monitoring, transfer of clinical data, and methods of remote clinician-patient interaction. Furthermore, healthcare and resources may be transferred by internet, telecommunications (eHealth), or via the use of mobile devices (mHealth) [5]. Telemedicine has been studied in clinical trials in the context of monitoring health conditions (e.g. heart failure, hypertension, and diabetes) [6, 7], provision of treatment or rehabilitation [8], provision of self-management and/or education [9, 10], specialist consultations for treatment or diagnosis [11], screening, or real-time assessment of clinical status [12]. In addition to eliminating the risk of transmitting airborne infection, further proposed benefits of telemedicine approaches are reduced healthcare costs, increased efficiency [13-15], and for patients, increased satisfaction by reduced waiting times, travel, time off work or child-care, and costs [16-18]. However, possible negative outcomes include clinician and/or patient anxieties about insufficient training, medico-legal vulnerability, and the technology itself, including data security [19-22].

So, what of the evidence? A comprehensive Cochrane review on the subject in 2015 of 94 trials, over 20,000 participants, and $500+$ pages in length was only able to conclude that telemedicine leads to similar health outcomes as face-to-face delivery of care with unclear effects on costs, and unclear acceptability by patients and healthcare professionals [4]. The sheer volume of studies, and the heterogeneous nature of technologies used provides a challenge for those summarising the evidence, and the resulting uncertainty about cost, acceptability, and safety is likely to have contributed to slow adoption of these technologies pre-COVID-19 [23].

Within the field of osteoporosis, some evidence exists for use of telemedicine approaches from countries with large land masses such as Australia and Canada where geography and distribution of appropriately skilled healthcare workers necessitates a remote approach to healthcare [24]. A recent mixed methods study of a Canadian telemedicine delivered osteoporosis programme identified that patient participants perceived high-quality care and valued the experience and credibility of the treating clinician, but also raised issues about the coordination of their care with investigation results and poor followup with allied health professionals such as physiotherapists [16]. In the UK, telephone consultations are promoted in clinical guidelines for follow-up consultations in Fracture Liaison Services to promote adherence to anti-osteoporosis drugs [25], although the evidence supporting the use of telephone interventions to increase adherence to bisphosphonates is mixed. Telephone consultation follow-up conducted as part of a wider intervention based on the osteoporosis coordinator role had a modest effect on self-reported adherence rates in a Canadian trial [26], but two larger American studies involving telephone follow-up by nurses and telephonic delivery of motivational interviewing designed specifically to increase adherence have not influenced either self-reported or filled prescription measures of adherence respectively [27, 28].
With osteoporosis outpatient and FLSs on pause, healthcare organisations have already moved to delivering new and follow-up consultations remotely, where staffing permits, by telephone or video [29]. Remote consultations have been described as particularly appropriate for chronic disease reviews and consultations where physical examination is not required [1], and are therefore highly applicable to osteoporosis services. Although the telephone is pervasive, inexpensive, minimally invasive, and frequently used, there is still relatively little evidence about the cost and clinical effectiveness of consulting in this way [2]. In UK primary care, evidence from a recent non-randomised experimental study suggests that although video and telephone consultations appear to be popular among patients and shorter than face-to-face consultations, they score lower on various quality measures such as seeking the patient's understanding of their health problem [30]. A recent systematic review identified only eight moderate to high-quality studies comparing video and telephone consultations, and identified that video consultations resulted in fewer medication errors, greater diagnostic accuracy, and improved decision-making accuracy when compared with telephone consultations, with no difference in patient reported outcomes [31]. However, there are also practical and logistical issues to consider in choosing the appropriate technology, and given that video consultations may require clinician and patient training, and in-person technical support, the use of video is recommended to supplement, rather than replace, telephone consultations [1].

One of the major limitations of the applicability of the evidence base for telemedicine in the context of osteoporosis relates to the characteristics of the populations studied. Although evidence on the use of telemedicine with patients aged 60 and over show predominantly positive results on patient behaviours, people with hearing, visual, or cognitive impairment are often excluded from clinical trials [32]. Furthermore, acceptance of health technology may also be related to a participants' understanding of their condition and their overall interest in their own health or health literacy; in a recent systematic review of the effect of telehealth tools on vulnerable populations, health literacy was only assessed in one of the included 18 studies [33]. Finally, there is a need for further research in remote consultations to consider the impact on other outcomes beyond healthcare use, and patient satisfaction to patient behaviours (such as drug adherence) and shared decision-making [34].

Presently, the context of COVID-19 is driving decisions about how healthcare is delivered. Organisations such as NHS England and Cochrane Effective Practice and Organisation of Care (EPOC) have produced rapid guidance for use of telephone consultations and implementation considerations for use of $\mathrm{m}$-Health technologies in response $[35,36]$. The transition from telehealth as a useful mechanism to employ during 'emergency situations', such as COVID-19, to 
telehealth being integrated into everyday clinical practice will be challenging. Such transition relies upon clinician education and training, funding to support telehealth provision, and the establishment of systems to support telehealth as a 'business as usual' strategy to routinely deliver care [37]. However, as yet we can only speculate how policy or organisation drivers, or patient demand, will change our behaviours post-COVID. While the current evidence base and guidelines are helpful, questions remain about the quality of care delivered remotely, the impact of remote care interactions on drug adherence, and the appropriateness and acceptability of care given remotely for the population of people with, or at risk of, osteoporosis. In the meantime, clinical services should maximise any opportunity to evaluate the impact of any urgent and unplanned changes in practice on patient and practitioner outcomes.

Code availability Not applicable.

Funding information ZP is funded by the National Institute for Health Research (NIHR) Clinician Scientist Award (CS-2018-18-ST2-010)/ NIHR Academy. FCM is part funded by the NIHR Clinical Research Network Clinical Research Scholar Programme. CJ is part funded by the NIHR Applied Research Collaboration West Midlands. The views expressed are those of the author(s) and not necessarily those of the National Health Service, the NIHR, or the Department of Health \& Social Care.

Data availability Not applicable.

\section{Compliance with ethical standards}

Conflicts of interest None.

\section{References}

1. Greenhalgh T, Wherton J, Shaw S, Morrison C (2020) Video consultations for covid-19. Br Med J. https://doi.org/10.1136/bmj. m998

2. Eccleston C, Blyth FM, Dear BF, Fisher EA, Keefe FJ, Lynch ME, Palermo TM, Reid MC, de C Williams AC (2020) Managing patients with chronic pain during the Covid-19 outbreak: considerations for the rapid introduction of remotely supported (e-health) pain management services. Pain 161:889-893

3. National Institute for Health Care Excellence (2020) COVID-19 rapid guideline: rheumatological autoimmune, inflammatory and metabolic bone disorders https://wwwniceorguk/guidance/ng167. Accessed 21 April 2020

4. Flodgren G, Rachas A, Farmer AJ, Inzitari M, Shepperd S (2015) Interactive telemedicine: effects on professional practice and health care outcomes. Cochrane Database Syst Rev

5. ATA (2020) Telehealth FAQs. American Telehealth Association (ATA) http://legacyamericantelemedorg/main/about/telehealthfaqs- Accessed 21 April 2020

6. Morguet AJ, Kühnelt P, Kallel A, Jaster M, Schultheiss H (2008) Impact of telemedical care and monitoring on morbidity in mild to moderate chronic heart failure. Cardiology 111:134-139. https:// doi.org/10.1159/000119701

7. Artinian NT, Flack JM, Nordstrom CK, Hockman EM, Washington OGM, Jen KC, Fathy M (2007) Effects of nursemanaged telemonitoring on blood pressure at 12-month followup among urban African Americans. Nurs Res 56:312-322. https://doi.org/10.1097/01.NNR.0000289501.45284.6e

8. Carey JR, Durfee WK, Bhatt E, Nagpal A, Weinstein SA, Anderson KM, Lewis SM (2007) Comparison of finger tracking versus simple movement training via telerehabilitation to alter hand function and cortical reorganization after stroke. Neurorehabil Neural Repair 21:216-232. https://doi.org/10.1177/1545968306292381

9. Bowles KH, Holland DE, Horowitz DA (2009) A comparison of inperson home care, home care with telephone contact and home care with telemonitoring for disease management. J Telemed Telecare 15:344-350. https://doi.org/10.1258/jtt.2009.090118

10. Salzsieder E, Augstein P (2011) The Karlsburg Diabetes Management System: translation from research to eHealth application. J Diabetes Sci Technol 5:13-22. https://doi.org/10.1177/ 193229681100500103

11. Beaver K, Tysver-Robinson D, Campbell M, Twomey M, Williamson S, Hindley A, Susnerwala S, Dunn G, Luker K (2009) Comparing hospital and telephone follow-up after treatment for breast cancer: randomised equivalence trial. BMJ 338:a3147. https://doi.org/10.1136/bmj.a3147

12. Sicotte C, Paré G, Morin S, Potvin J, Moreault M (2011) Effects of home telemonitoring to support improved care for chronic obstructive pulmonary diseases. Telemed J E Health 17:95-103. https:// doi.org/10.1089/tmj.2010.0142

13. Pinto A, Almeida JP, Pinto S, Pereira J, Oliveira AG, de Carvalho $M$ (2010) Home telemonitoring of non-invasive ventilation decreases healthcare utilisation in a prospective controlled trial of patients with amyotrophic lateral sclerosis. J Neurol Neurosurg Psychiatry 81:1238-1242. https://doi.org/10.1136/jnnp.2010. 206680

14. Elliott RA, Barber N, Clifford S, Horne R, Hartley E (2008) The cost effectiveness of a telephone-based pharmacy advisory service to improve adherence to newly prescribed medicines. Pharm World Sci 30:17-23. https://doi.org/10.1007/s11096-007-9134-y

15. Giordano A, Scalvini S, Zanelli E, Corrà U, Longobardi GL, Ricci VA, Baiardi P, Glisenti F (2009) Multicenter randomised trial on home-based telemanagement to prevent hospital readmission of patients with chronic heart failure. Int J Cardiol 131:192-199. https://doi.org/10.1016/j.ijcard.2007.10.027

16. Palcu P, Munce S, Jaglal SB, Allin S, Chishtie JA, Silverstein A, Kim S (2020) Understanding patient experiences and challenges to osteoporosis care delivered virtually by telemedicine: a mixed methods study. Osteoporos Int 31:351-361. https://doi.org/10. 1007/s00198-019-05182-5

17. Finkelstein SM, Speedie SM, Zhou X, Potthoff S, Ratner ER (2011) Perception, satisfaction and utilization of the VALUE home telehealth service. J Telemed Telecare 17:288-292. https://doi. org/10.1258/jtt.2011.100712

18. Agha Z, Schapira RM, Laud PW, McNutt G, Roter DL (2009) Patient satisfaction with physician-patient communication during telemedicine. Telemed J E Health 15:830-839. https://doi.org/10. 1089/tmj.2009.0030

19. Murphy JFA (2019) Telephone medical advice. Ir Med J 112:863

20. Lateef F (2011) The practice of telemedicine: medico-legal and ethical issues. Ethics Med 27:17-24

21. Foster A, Horspool KA, Edwards L, Thomas CL, Salisbury C, Montgomery AA, O'Cathain A (2015) Who does not participate in telehealth trials and why? A cross-sectional survey. Trials 16: 258. https://doi.org/10.1186/s13063-015-0773-3

22. Terry M (2009) Medical identity theft and telemedicine security. Telemed e-Health 15:928-933 
23. Rada G (2015) Telemedicine: are we advancing the science? Cochrane Database Syst Rev:ED000105. https://oi.org/10.1002/ 14651858.ED000105

24. Slater H, Dear BF, Merolli MA, Li LC, Briggs AM (2016) Use of eHealth technologies to enable the implementation of musculoskeletal models of care: evidence and practice. Best Pract Res Clin Rheumatol 30:483-502. https://doi.org/10.1016/j.berh.2016.08. 006

25. Gallacher S, Alexander S, Beswetherick N, Carr W, Durber A, Gittoes N, Gray A, Javaid K, Kendrick D, Lindsey J, Ong T, Smith A, Stone M, Tanna N, Thurston A, Wardell F (2019) Effective secondary prevention of fragility fractures: clinical standards for fracture liaison services. Royal Osteoporosis Society, pp $1-44$

26. Jaglal SB, Donescu OS, Bansod V, Laprade J, Thorpe K, Hawker G, Majumdar SR, Meadows L, Cadarette SM, Papaioannou A, Kloseck M, Beaton D, Bogoch E, Zwarenstein M (2012) Impact of a centralized osteoporosis coordinator on post-fracture osteoporosis management: a cluster randomized trial. Osteoporos Int 23: 87-95. https://doi.org/10.1007/s00198-011-1726-7

27. Schousboe J, DeBold R, Kuno L, Weiss T, Chen Y, Abbott T (2005) Education and phone follow-up in postmenopausal women at risk for osteoporosis: effects on calcium intake, exercise frequency, and medication use. Dis Manag Health Outcomes 13:395-404. https://doi.org/10.2165/00115677-200513060-00004

28. Solomon DH, Iversen MD, Avorn J, Gleeson T, Brookhart MA, Patrick AR, Rekedal L, Shrank WH, Lii J, Losina E, Katz JN (2012) Osteoporosis telephonic intervention to improve medication regimen adherence: a large, pragmatic, randomized controlled trial. Arch Intern Med 172:477-483. https://doi.org/10.1001/ archinternmed.2011.1977

29. Saltzman J (2020) In a huge shift because of coronavirus, most doctors now 'seeing' patients by phone or video - The Boston Globe. 2020

30. Hammersley V, Donaghy E, Parker R, McNeilly H, Atherton H, Bikker A, Campbell J, McKinstry B (2019) Comparing the content and quality of video, telephone, and face-to-face consultations: a non-randomised, quasi-experimental, exploratory study in UK primary care. Br J Gen Pract 69:595-604. https://doi.org/10.3399/ bjgp19X704573

31. Rush KL, Howlett L, Munro A, Burton L (2018) Videoconference compared to telephone in healthcare delivery: a systematic review. Int J Med Inform 118:44-53. https://doi.org/10.1016/j.ijmedinf. 2018.07.007

32. van den Berg N, Schumann M, Kraft K, Hoffmann W (2012) Telemedicine and telecare for older patients - a systematic review. Maturitas 73:94-114. https://doi.org/10.1016/j.maturitas.2012.06. 010

33. Parker S, Prince A, Thomas L, Song H, Milosevic D, Harris MF (2018) Electronic, mobile and telehealth tools for vulnerable patients with chronic disease: a systematic review and realist synthesis. BMJ Open 8:e019192. https://doi.org/10.1136/bmjopen-2017019192

34. Rahimi SA, Menear M, Robitaille H, Légaré F (2017) Are mobile health applications useful for supporting shared decision making in diagnostic and treatment decisions? Glob Health Action 10. https:// doi.org/10.1080/16549716.2017.1332259

35. NHS England (2020) Using phone consultations 2020

36. 'Briefly Summarised', Cochrane Norway (2020) Mobile phones for health workers in primary care: implementation considerations 2020

37. Smith AC, Thomas E, Snoswell CL, Haydon H, Mehrotra A, Clemensen J, Caffery LJ (2020) Telehealth for global emergencies: implications for coronavirus disease 2019 (COVID-19). J Telemed Telecare:1357633X2091656. https://doi.org/10.1177/ 1357633 X20916567

Publisher's note Springer Nature remains neutral with regard to jurisdictional claims in published maps and institutional affiliations. 